\title{
Treatment of bone defect with calcium phosphate cement subsequent to tumor curettage in pediatric patients
}

\author{
TOMOKI NAKAMURA, AKIHIKO MATSUMINE, KUNIHIRO ASANUMA, \\ TAKAO MATSUBARA and AKIHIRO SUDO
}

Department of Orthopaedic Surgery, Mie University Hospital, Tsu, Mie 514-8507, Japan

Received January 5, 2015; Accepted September 17, 2015

DOI: 10.3892/ol.2015.3855

\begin{abstract}
The aim of the present study was to investigate the mid- to long-term clinical performance of calcium phosphate cement (CPC) in the treatment of benign bone tumors in pediatric patients with a follow-up of at least 2-years. The cases of 33 patients with benign bone tumors treated by curettage and subsequent implantation of CPC were retrospectively reviewed. The patients consisted of 13 males and 20 females, with a median age of 13 years and median follow-up time of 79 months. All patients were alive at the time of review. No toxicity was detected in routine blood tests. Radiography was used to confirm that CPC was well adapted to the surrounding host bone, although the resorbability of CPC was not obtained for all patients at the final follow-up. Local tumor recurrence occurred in 4 patients. None of the patients reported post-operative fractures. In total, 6 patients required a second surgical procedure, as follows: 4 patients in whom local tumor recurrence occurred; 1 patient with post-operative superficial wound infection, who underwent wound debridement; and 1 patient that required the removal of CPC due to deep infection at the proximal humerus. All patients had regained full physical function without any pain at the final follow-up. The present study recommends that the properties of CPC should be taken into consideration and applied to the reconstruction of bone defects subsequent to curettage of bone tumors.
\end{abstract}

\section{Introduction}

Benign bone tumors mainly occur in children and adolescents, and almost $42 \%$ of all bone lesions, including benign and malignant etiologies, occur in the first two decades of life $(1,2)$. However, this figure may be underestimated, as the majority of benign tumors are not registered in clinical databases,

Correspondence to: Dr Tomoki Nakamura, Department of Orthopaedic Surgery, Mie University Hospital, 2-174 Edobashi, Tsu, Mie 514-8507, Japan

E-mail: tomoki66@clin.medic.mie-u.ac.jp

Key words: calcium phosphate cement, pediatric patients, benign bone tumor, complication due to the asymptomatic clinical features that benign tumors present with $(1,2)$. Surgical treatment is required when patients demonstrate pathological fractures or locally aggressive benign tumors, including giant cell tumors and chondroblastoma (1-3). Additionally, symptomatic patients complaining of recurrent pain or exhibiting a restricted range of motion in the affected joints are considered for surgical treatment $(1,2,4)$. There are various surgical treatment strategies for benign bone tumors, consisting of curettage, curettage with autologous/allogeneic bone grafting, and curettage with artificial bone grafting (3-8). Calcium phosphate cement (CPC) is an injectable biocompatible bone substitute that has been used for various applications in orthopedic surgery, due to its easy handling, high mechanical strength and good osteoconductive biological properties (4,6-9). A previous study reported that CPC offered a useful bone substitute for the treatment of bone and soft tissue tumors; however, the follow-up time was short (median follow-up, 18.5 months) (6).

Pediatric bone tumors remain a challenging field for orthopedic tumor surgeons. Due to the active nature of meta-epiphyseal tumors and iatrogenic damage to the growth plate, surgery performed on this type of tumor may often lead to progressive limb deformities $(3,10-12)$. Special consideration must be provided to pediatric tumor patients, not only for local tumor control, but also for the long-term functional and developmental outcome of the limb (3).

The aim of the present study was to investigate the mid- to long-term clinical performance of CPC in the treatment of benign bone tumors in pediatric patients with a follow-up of at least 2-years. The present study was approved by the Ethics Committee of Mie University Hospital (Tsu, Japan) and written informed consent was obtained from all patients.

\section{Patients and methods}

Patient characteristics. The present study retrospectively reviewed the cases of 33 patients with benign bone tumors treated by curettage and subsequent implantation of CPC at the Mie University Hospital between January 2001 and January 2011, with at least 2-years of follow-up. This is more than the number of patients included in a previous study that reported a mean follow-up time of 18.5 months (6). Medical records were predominantly used to review the cases. A total of 13 males and 20 females were reviewed in the present study (median age, 
Table I. Patient characteristics and detail of reconstruction for bone defect subsequent to curettage.

\begin{tabular}{|c|c|c|c|c|c|c|c|}
\hline $\begin{array}{l}\text { Case } \\
\text { no. }\end{array}$ & Age & Gender & Location & Diagnosis & Type of CPC & $\begin{array}{l}\text { Volume of CPC, } \\
\mathrm{ml}\end{array}$ & Augmentation \\
\hline 1 & 16 & $\mathrm{~F}$ & Patella & $\mathrm{CB}$ & CPC-R & 5.0 & \\
\hline 2 & 7 & $\mathrm{~F}$ & Pharanx & $\mathrm{EC}$ & CPC-R & 1.0 & \\
\hline 3 & 16 & M & Femur & $\mathrm{CB}$ & CPC-R & 4.0 & \\
\hline 4 & 18 & $\mathrm{~F}$ & Pelvis & $\mathrm{CB}$ & CPC-R & 6.0 & \\
\hline 5 & 15 & M & Pelvis & $\mathrm{ABC}$ & CPC-R & 55.0 & \\
\hline 6 & 10 & M & Femur & $\mathrm{SBC}$ & CPC-R & 13.0 & \\
\hline 7 & 6 & $\mathrm{~F}$ & Pharanx & $\mathrm{EC}$ & CPC-R & 0.5 & \\
\hline 8 & 8 & $\mathrm{~F}$ & Humerus & $\mathrm{SBC}$ & CPC-R & 2.0 & \\
\hline 9 & 12 & $\mathrm{M}$ & Tibia & OFD & CPC-R & 6.0 & \\
\hline 10 & 16 & $\mathrm{~F}$ & Pelvis & $\mathrm{ABC}$ & $\mathrm{CPC}$ & 10.0 & \\
\hline 11 & 18 & $\mathrm{~F}$ & Ulna & GCT & $\mathrm{CPC}$ & 1.0 & \\
\hline 12 & 8 & $\mathrm{~F}$ & Fibula & $\mathrm{EC}$ & $\mathrm{CPC}$ & 20.0 & \\
\hline 13 & 10 & M & Calcaneus & $\mathrm{SBC}$ & CPC-R & 12.0 & \\
\hline 14 & 16 & $\mathrm{~F}$ & Humerus & $\mathrm{SBC}$ & CPC-R & 14.0 & \\
\hline 15 & 13 & M & Humerus & $\mathrm{ABC}$ & CPC-R & 24.0 & \\
\hline 16 & 12 & M & Humerus & $\mathrm{SBC}$ & CPC-R & 5.0 & \\
\hline 17 & 15 & $\mathrm{~F}$ & Femur & FD & CPC-R & 54.0 & IM nail \\
\hline 18 & 13 & $\mathrm{~F}$ & Calcaneus & $\mathrm{SBC}$ & CPC-R & 10.0 & \\
\hline 19 & 15 & $\mathrm{~F}$ & Femur & GCT (rec.) & CPC-R & 70.0 & \\
\hline 20 & 16 & $\mathrm{~F}$ & Femur & NOF & CPC-R & 6.0 & \\
\hline 21 & 16 & $\mathrm{~F}$ & Pharanx & EC & CPC-R & 3.0 & \\
\hline 22 & 4 & M & Femur & $\mathrm{EC}$ & CPC & 5.0 & \\
\hline 23 & 17 & M & Humerus & SBC (rec.) & CPC-R & 50.0 & \\
\hline 24 & 12 & $\mathrm{~F}$ & Pharanx & $\mathrm{EC}$ & CPC-R & 2.0 & \\
\hline 25 & 15 & $\mathrm{~F}$ & Tibia & OFD & CPC-R & 23.0 & \\
\hline 26 & 4 & M & Femur & $\mathrm{SBC}$ & CPC-R & 6.0 & \\
\hline 27 & 11 & $\mathrm{~F}$ & Femur & $\mathrm{ABC}$ & $\mathrm{CPC} / \mathrm{CHA}$ & 10.0 & \\
\hline 28 & 16 & $\mathrm{~F}$ & Femur & GCT (rec.) & $\mathrm{CPC} / \mathrm{CHA}$ & 30.0 & CHS \\
\hline 29 & 11 & M & Tibia & OFD & CPC-R & 12.0 & \\
\hline 30 & 11 & $\mathrm{~F}$ & Calcaneus & $\mathrm{SBC}$ & CPC-R & 12.0 & \\
\hline 31 & 18 & M & Femur & $\mathrm{ABC}$ & CPC-R & 12.0 & Plate \\
\hline 32 & 12 & M & Femur & GCT & CPC-R/CHA & 18.0 & \\
\hline 33 & 12 & $\mathrm{~F}$ & Tibia & NOF & CPC-R & 18.0 & \\
\hline
\end{tabular}

ABC, aneurysmal bone cyst; CB, chondroblastoma; EC, enchondroma; GCT, giant cell tumor; FD, fibrous dysplasia; NOF, non-ossifying fibroma; OFD, osteofibrous fysplasia; SBC, solitary bone cyst; rec., recurrence; CPC, calcium phosphate cement, BIOPEX ${ }^{\circledR}$; CPC-R, calcium phophate cement, BIOPEX-R ${ }^{\circledR}$; IM, intramedullary; CHA, calcium hydroxyapatite ceramic; CHS, compression hip screw.

13 years; range, $4-18$ years) (Table I). The median follow-up time was 79 months (mean, 79 months; range, 25-151 months). The bone tumors the patients presented with consisted of 9 solitary bone cysts, 6 enchondroma lesions, 5 aneurysmal bone cysts, 4 giant cell tumors, 3 chondroblastoma lesions, 3 osteofibrous dysplasia lesions, 2 non-ossifying fibroma lesions, and 1 fibrous dysplasia lesion. The location of the tumor lesions were as follows: Femur $(n=11)$; humerus $(n=5)$; tibia $(n=4)$; phalanx $(n=4)$; pelvis $(n=3)$; calcaneus $(n=3)$; and fibula, patella or ulna $($ all $\mathrm{n}=1)$. In total 30 patients possessed primary bone tumors and 3 patients possessed recurrent tumors.

The present study was performed following ethical principles of research.
CPC development. BIOPEX ${ }^{\circledR}$ or BIOPEX-R ${ }^{\circledR}$ (HOYA Technosurgical Corporation, Tokyo, Japan) was the CPC used to fill intramedullary bone defects. Briefly, CPC $(6 \mathrm{ml})$ was made by mixing the powder component of Biopex- $\mathrm{R}^{\circledR}$, containing a-tricalcium phosphate, tetracalcium phosphate and calcium hydrogen phosphate dehydrate, with the liquid component of Biopex- $\mathrm{R}^{\circledR}$, containing sodium succinate and sodium chonroitin sulfate. The two components were mixed at an appropriate powder-to-liquid ratio $(\mathrm{P} / \mathrm{L}=2.0-4.5)$ for a few minutes (typical quantities: $10 \mathrm{~g}$ powder and 2-4 $\mathrm{ml}$ liquid). To allow reservation of the Biopex- $\mathrm{R}^{\circledR}$ cement at room temperature, magnesium phosphate and sodium hydrogen sulfite were added to the powder component (6). The compressive 

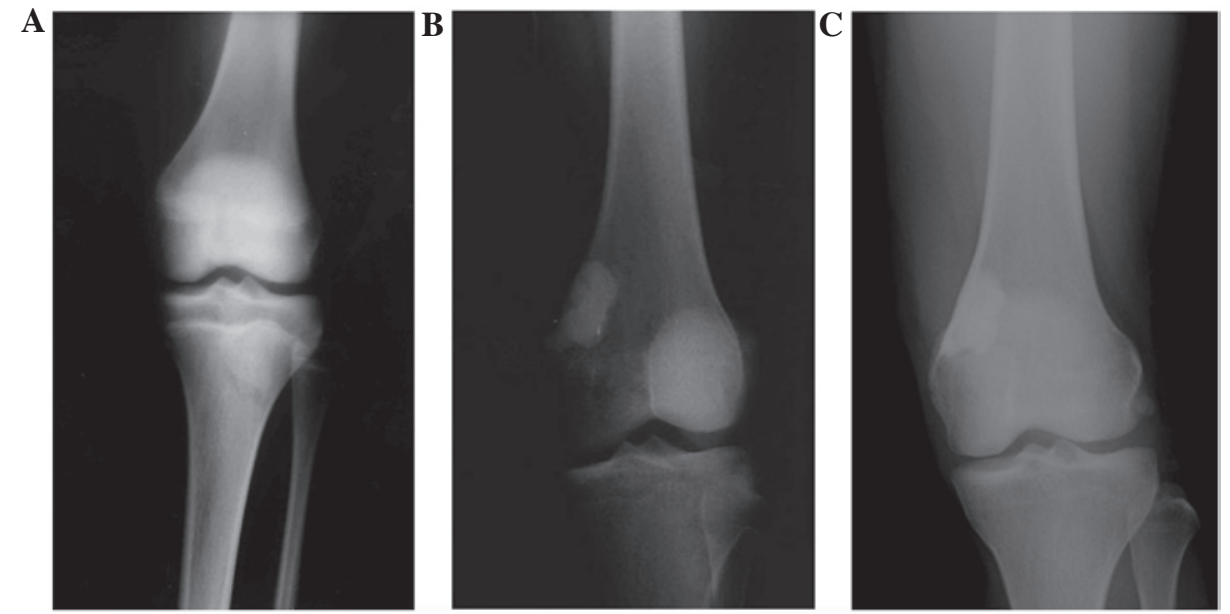

Figure 1. Radiograph showing non-ossifying fibroma of the left distal femur (case 20). (A) The tumor was located in the distal part of femur. (B) CPC was implanted subsequent to curettage. (C) Subsequent to 10 years, CPC was radiographycally well adapted to the surrounding host bone, although the resorbability of CPC has not been completely obtained. CPC, calcium phosphate cement.

strength of the cured materials was $\sim 65 \mathrm{MPa} 3$ days following mixing, reaching a final strength of $>70 \mathrm{MPa} 1$ week following mixing $(13,14)$. Biopex- $\mathrm{R}^{\circledR}$ replaced Biopex ${ }^{\circledR}$ in 2002 at Mie University Hospital.

\section{Results}

Surgical treatment. Surgery was performed using a tourniquet in 19 patients, and without in 14 patients. Tumor curettage was performed using a curette (MIZUHO Corporation, Tokyo, Japan) and an airtome (Zimmer K.K., Tokyo, Japan) until healthy cancellous bone was visualized. CPC was injected subsequent to curettage (median volume, $10 \mathrm{ml}$; range, 0.5-70 ml) for the reconstruction of bony defects. Internal fixation was performed in 3 patients. The window of the cortical bone at the tumor site must be large enough to allow adequate curettage of the tumor until underlying normal bone is exposed. After curettage, an internal fixation was inserted. CPC was implanted in the bone defect. Intramedullary nail and compression hip screw was inserted to prevent post-operative fractures in 2 patients (case 17 and 28). Plate fixation was performed in 1 patient, who presented with a pre-operative pathological fracture (case 31). Calcium hydroxyapatite ceramic (CHA) in granular form (BONECERAM ${ }^{\circledR}$; Olympus Corporation, Tokyo, Japan) was used in combination with CPC in 3 patients (case 27, 28 and 32) to reduce tumor spread in high-risk patients.

Clinical outcome. All patients were alive at the time of review (Table II). No toxicity was detected in routine blood tests, including white blood cell (normal range, 3,900-6,600 cells $/ \mathrm{mm}^{2}$ ), C-reactive protein (normal range, $0.3 \mathrm{mg} / \mathrm{dl}$ ) and creatinine (normal range, $0.60-1.40 \mathrm{mg} / \mathrm{dl}$ ) tests. Radiography confirmed that CPC was well adapted to the surrounding host bone in all patients, an example of which is shown in Fig. 1. However, the resorbability of the CPC had not been determined in all cases at the final follow-up. Local tumor recurrence occurred in 4 patients (cases 8, 9, 28 and 32). None of the patients reported post-operative fractures. A total of 20 patients, in whom tumors were located in the lower extremities, required between 1-16 weeks to bear the full weight subsequent to surgery. There was no requirement for intense physical therapy in the majority of patients. In total, 1 patient with large recurrent giant cell tumor of the bone (case 28) required 8 weeks of cast fixation followed by physical therapy for 1 month, as the residual bone stock was too scarce to allow early weight bearing following curettage of the bone tumor (Fig. 2), and 1 patient (case 32), in whom CPC was implanted at a fracture site, required physical therapy for 2 months subsequent to 6 weeks of cast fixation (Fig. 3).

In total, 6 patients required a second surgery, as follows: 4 patients with local tumor recurrence (cases 8, 9, 28 and 32); 1 patient with post-operative superficial wound infection (case 5) that underwent wound debridement; and 1 patient with a simple bone cyst at the proximal humerus that required the removal of $\mathrm{CPC}$ and the implantation of antibiotic-impregnated (vancomycin) CHA due to deep infection (case 23).

The limb length discrepancy was $1.5 \mathrm{~cm}$ in 1 patient with recurrent giant cell tumor (case 28; Fig. 2) and $2.0 \mathrm{~cm}$ in 1 patient with giant cell tumor accompanying a varus deformity of the femur (case 32; Fig. 3). Neither patient was restricted in daily life. All patients had regained full physical function without any pain at the final follow-up.

\section{Discussion}

Autologous bone grafting for a bone defect following curettage of a bone tumor is the gold standard as a reconstruction method, as it guarantees rapid graft incorporation and bone remodeling $(4,15)$. The advantages of CPC include a fast setting time, excellent moldability and good osteoconductivity (4,6-9). The early structural support that CPC offers is beneficial for large bone defects at risk of fracture. The compressive strength of CPC ranges between 26 and $70 \mathrm{MPa}$, which is comparable to that of cancellous bone $(16,17)$. Studies have indicated that the injection of CPC can increase the strength of a fractured vertebral body to that of an intact vertebral body $(18,19)$. Thordarson et al reported the superior compressive strength of a calcaneal fracture construct when it was augmented with CPC (20). Therefore, the present study suggests that 


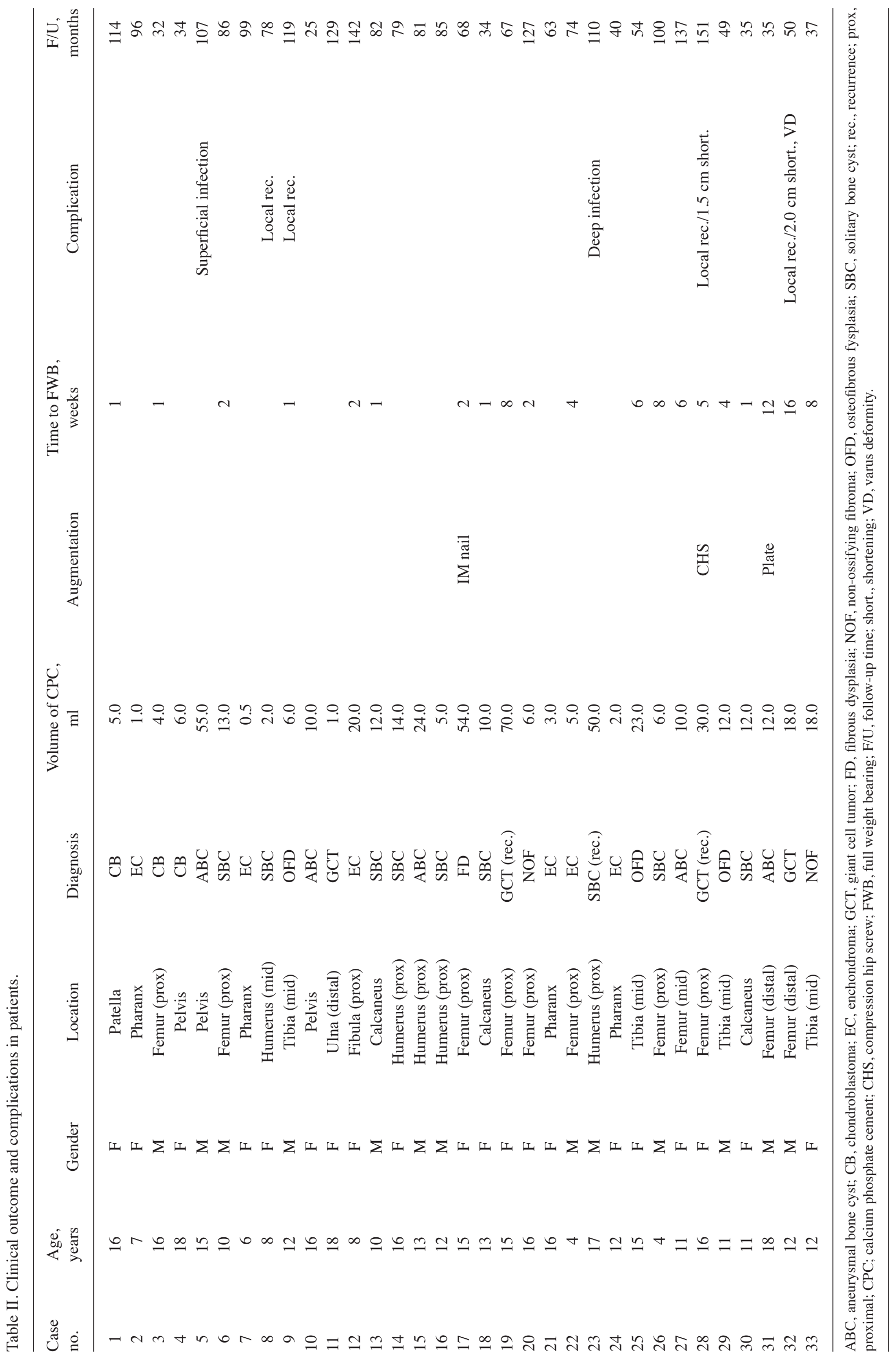



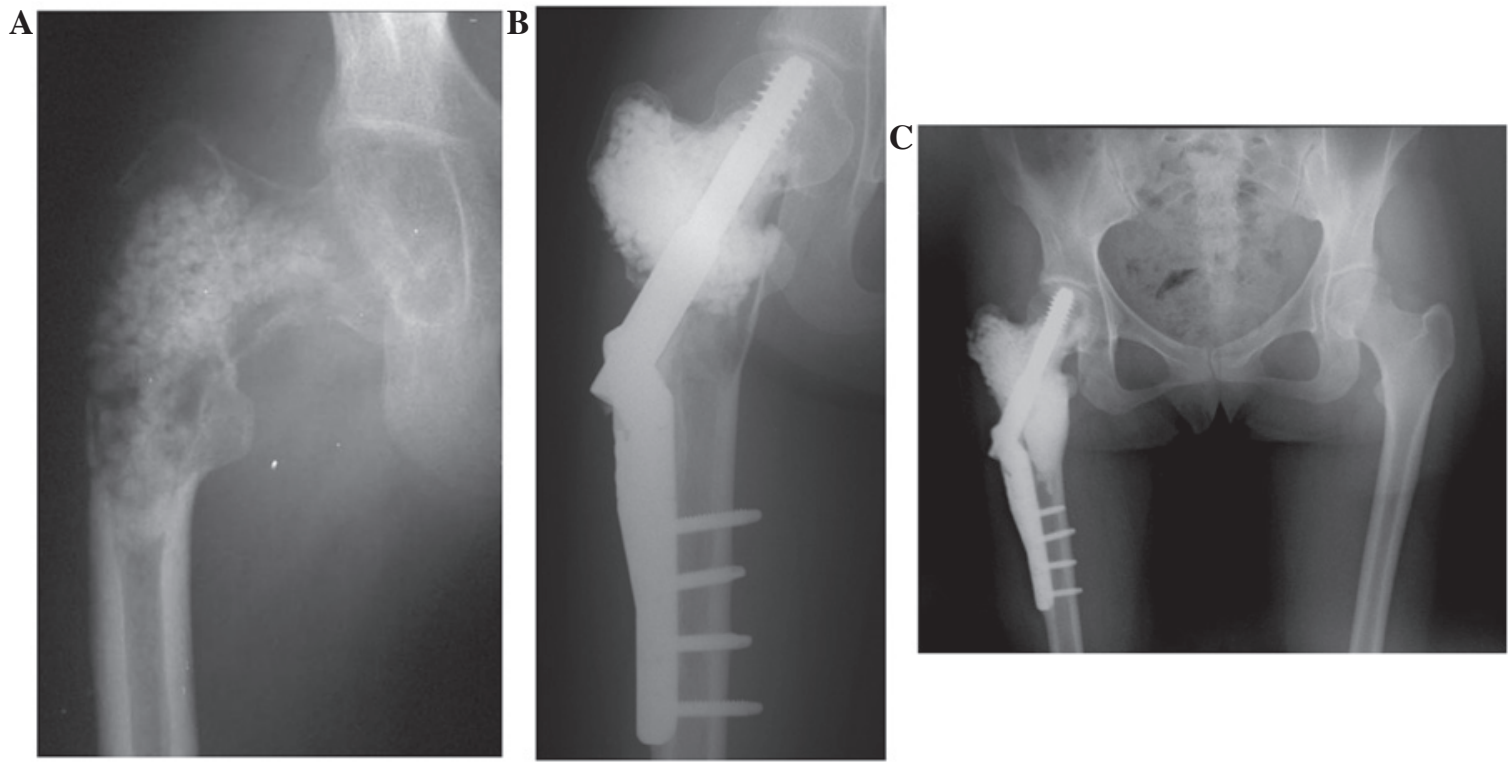

Figure 2. Radiograph showing recurrent giant cell tumor of the right proximal femur (case 28). (A) The patient was referred to Mie University Hospital (Tsu, Japan) following recurrence of giant cell tumor at proximal part of femur with pathological fracture. (B) Calcium phosphate cement and calcium hydroxyapatite ceramic were implanted and compression hip screw was inserted after curettage. Additional surgery was needed due to local recurrence. (C) At the time of review, limb length discrepancy was $1.5 \mathrm{~cm}$, although the patient can work without any disability as a nurse.
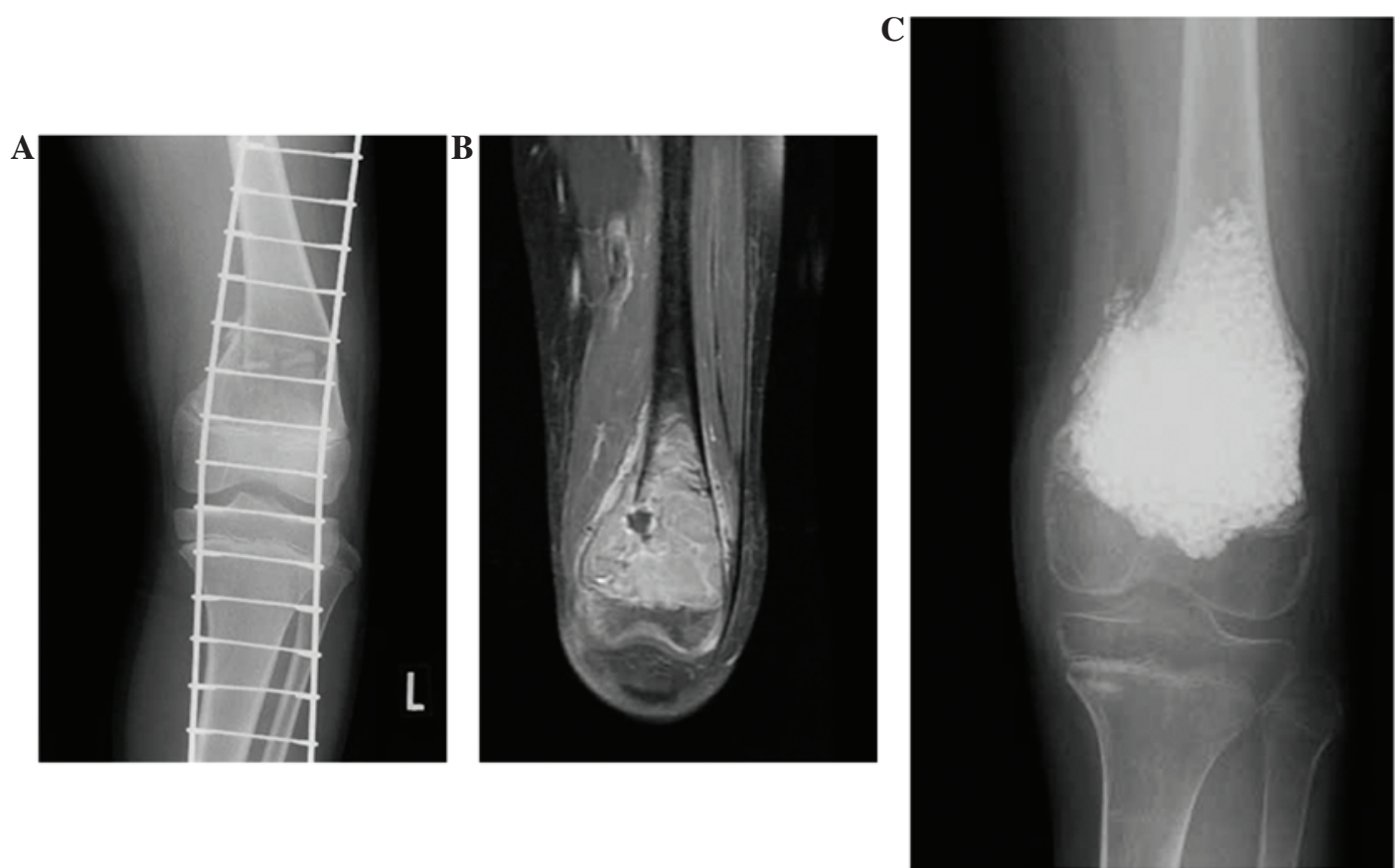

Figure 3. Radiograph showing giant cell tumor of the left distal femur (case 32). (A) The patient was referred to Mie University Hospital (Tsu, Japan) following pathological fracture. (B) The tumor was located in the distal region of the femur and adjacent to distal femoral physis. (C) Calcium phosphate cement and calcium hydroxyapatite ceramic were implanted in to the bone defect following curettage of the bone tumor. At the time of review, the limb length discrepancy was $2.0 \mathrm{~cm}$, with varus deformity of the femur, although the patient plays tennis at junior high school.

full weight bearing can be allowed several days subsequent to surgery when CPC is injected into a cavity subsequent to curettage of a bone tumor of flat bone, including tumors of the calcaneus and patella. However, the results of an experimental study using rabbits indicate that, although CPC increases the torsional strength of the shaft of long bones in the early phase, the resultant strength is not adequate to preclude the requirement for external fixation (14). When CPC is implanted into a cavity that occupies more than one-half of the medullary cavity of long bones at lower extremities, the present study recommends waiting for $\geq 3$ weeks following surgery prior to full weight bearing. Furthermore, when a tumor is localized in metaphyseal or diaphyseal bone, metal augmentation, including plate fixation, should be considered; unless the metal augumentation is a hindrance to growth, as pediatric patients are active and so there is a risk of post-operative fracture. 
The presence of an active physis within the zone of resection and iatrogenic damage to the growth plate has been linked to growth associated complications and progressive limb deformities $(3,10-12)$. In total, 2 patients (cases 28 and 32) reported in the present study demonstrated limb length discrepancy. However, this may be associated with pre-operative pathological fractures resulting in leg shortening and deformity in the 2 patients. Furthermore, the patient that presented with a giant cell tumor at the distal region of the femur (case 32), did not undergo correction osteotomy for the angulated deformity due to pathological fracture, as metal reinforcement may be a cause of growth arrest of the femur. Although post-operative deformity of the bone was not observed in the remaining 31 patients in the present study, additional follow-up is essential until the closure of the growth plate is observed.

The present study described how CPC may demonstrate a therapeutic potential as a useful bone substitute in pediatric patients that present with benign bone tumors. However, there are several disadvantages of CPC. First, CPC remains expensive despite efforts to reduce the cost. Second, even at the median 6 years follow-up described in the present study, the resorbability of CPC was far from complete. Graft material, such as CPC, may impede future surgical reconstructive alternatives, including joint replacement. Therefore the properties of the CPC must be taken into consideration and applied to the reconstruction of bone defects after curettage of bone tumors.

\section{References}

1. Wyers MR: Evaluation of pediatric bone lesions. Pediatr Radiol 40: 468-473, 2010.

2. Vlychou M and Athanasou NA: Radiological and pathological diagnosis of pediatric bone tumors and tumor-like lesions. Pathology 40: 196-216, 2008

3. Wallace MT and Henshaw RM: Results of cement versus bone graft reconstruction after intralesional curettage of bone tumors in the skeletally immature patient. J Pediatr Orthop 34: 92-100, 2014.

4. Kirschner HJ, Obermary F, Schaefer J and Lieber J: Treatment of benign bone defects in children with silicate-substituted calcium phosphate (SiCaP). Eur J Pediatr Surg 22: 143-147, 2012.

5. George B, Abudu A, Grimer RJ, Carter SR and Tillman RM: The treatment of benign lesions of the proximal femur with non-vascularised autologous fibular strut grafts. J Bone Joint Surg Br 90: 648-651, 2008.
6. Matsumine A, Kusuzaki K, Matsubara T, Okamura A, Okuyama N, Miyazaki S, Shintani K and Uchida A: Calcium phosphate cement in musculoskeletal tumor surgery. J Surg Oncol 93: 212-220, 2006.

7. Yasuda M, Masada K and Takeuchi E: Treatment of enchondroma of the hand with injectable calcium phosphate bone cement J Hand Surg 31: 98-102, 2006.

8. Strauss EJ, Pahk B, Kummer FJ and Egol K: Calcium phosphate cement augmentation of the femoral neck defect created after dynamic hip screw removal. J Orthop Trauma 21: 295-300, 2007.

9. Ambard AJ and Mueninghoff L: Calcium phosphate cement: Review of mechanical and biological properties. J Prosthodont 15: 321-328, 2006.

10. Ozaki T, Hillmann A, Linder N and Winkelmann W: Cementation of primary aneurismal bone cysts. Clin Orthop Relat Res 337: 240-248, 1997.

11. Lin PP, Thenappan A, Deavers MT, Lewis VO and Yasko AW: Treatment and prognosis of chondroblastoma. Clin Orthop Relat Res 438: 103-109, 2005.

12. Hajdu S, Schwendenwein E, Kaltenecker G, László I, Lang S, Vécsei V and Sarahrudi K: The effect of drilling and screw fixation of the growth plate - an experimental study in rabbits. J Orthop Res 29: 1834-1839, 2011.

13. Ikeuchi M, Yamamoto H, Shibata T and Otani M: Mechanical augmentation of the vertebral body by calcium phosphate cement injection. J Orthop Sci 6: 39-45, 2001.

14. Mizobuchi H, Tani T, Takemasa R, Yamamoto H and Sonobe H: Mechanical properties of the femur filled with calcium phosphate cement under torsional loading: A model in rabbits. J Orthop Sci 7: 562-569, 2002.

15. Matsumine A, Myoui A, Kusuzaki K, Araki K, Seto M, Yoshikawa $\mathrm{H}$ and Uchida A: Calcium hydroxyapatite ceramic implants in bone tumour surgery. J Bone Joint Surg 86: 719.725, 2004.

16. Welch RD, Zhang $\mathrm{H}$ and Bronson DG: Experimental tibial plateau fractures augumented with calcium phosphate cement or autologous bone graft. J Bone Joint Surg Am 85-A: 222-231, 2003.

17. Larsson S and Bauer TW: Use of injectable calcium phosphate cement for fracture fixation: A review. Clin Orthop Relat Res 395: 23-32, 2002

18. Lim TH, Brebach GT, Renner SM, Kim WJ, Kim JG, Lee RE, Andersson GB and An HS: Biomechanical evaluation of an injectable calcium phosphate cement for vertebroplasty. Spine (Phila Pa 1976) 27: 1297-1302, 2002.

19. Tomita S, Kin A, Yazu M and Abe M: Biomechanical evaluation of kyphoplasty and vertebroplasty with calcium phosphate cement in a simulated osteoporotic compression fracture. J Orthop Sci 8: 192-197, 2003.

20. Thordarson DB, Hedman TP, Yetkinler DN, Eskander E, Lawrence TN and Poser RD: Superior compressive strength of a calcaneal fracture construct augmented with remodelable cancellous bone cement. J Bone Joint Surg Am 81: 239-246, 1999. 